\title{
Endoscopic Full Thickness Resection for Duodenal Neuroendocrine Tumor
}

Harwani Y Tamboliya G Gajera N

Digest Endosc 2019;10:197-198
Address for correspondence Noble Institute of Gastroenterology, Ahmedabad, Gujarat, India (e-mail: bhageerath@outlook.com).

\begin{abstract}
Introduction Recently endoscopic full thickness resection (EFTR) device with inbuilt Ovesco clip and mounted snare has been introduced for lower gastrointestinal lesions but its feasibility for upper gastrointestinal lesions is still doubted and is not commercially available. We performed EFTR by using Ovesco clip followed by snare polypectomy for one $\mathrm{cm}$ duodenal neuroendocrine tumor (NET) which is $1.5-\mathrm{cm}$ proximal to papilla.

Case 55-year-old male was incidentally detected to have biopsy proven $1 \mathrm{~cm}$ well-differentiated duodenal NET, $1.5-\mathrm{cm}$ proximal to papilla in duodenum with positive DOTA positron emission tomography-computed tomography (PET-CT) scan. Endoscopic ultrasound suggestive of $9 \mathrm{~mm} \times 4 \mathrm{~mm}$ lesion arising from submucosa and adherent to mascularis propria. Surgical treatment in the form of Whipple's procedure, endoscopic submucosal dissection (ESD) and EFTR all modalities of treatment were discussed with patient. EFTR was preferred over ESD considering its small size and adherence to muscularis propria.

Discussion Duodenal NET have to be removed irrespective of size and symptoms as they have potential to metastasize. Surgical duodenectomy or Whipple's procedure are major surgical procedures which are associated with considerable morbidity for asymptomatic small (less than $2 \mathrm{~cm}$ ) duodenal NET. ESD and EFTR are suitable options for small duodenal lesions. ESD may be challenging for lesion spread beyond submucosa and may lead to perforation of the bowel. Perforation in second part of the duodenum may lead to serious consequences. Compared to ESD, EFTR is a simple technique based on band and cut technique used for endoscopic mucosal resection (EMR) and safe for such type of patients.

Conclusion EFTR is a suitable option than Whipple's procedure for lesions up to $2 \mathrm{~cm}$ in duodenum, can be preferred over ESD for lesions spread beyond submucosa. EFTR is a relatively simple and safe technique.
\end{abstract}




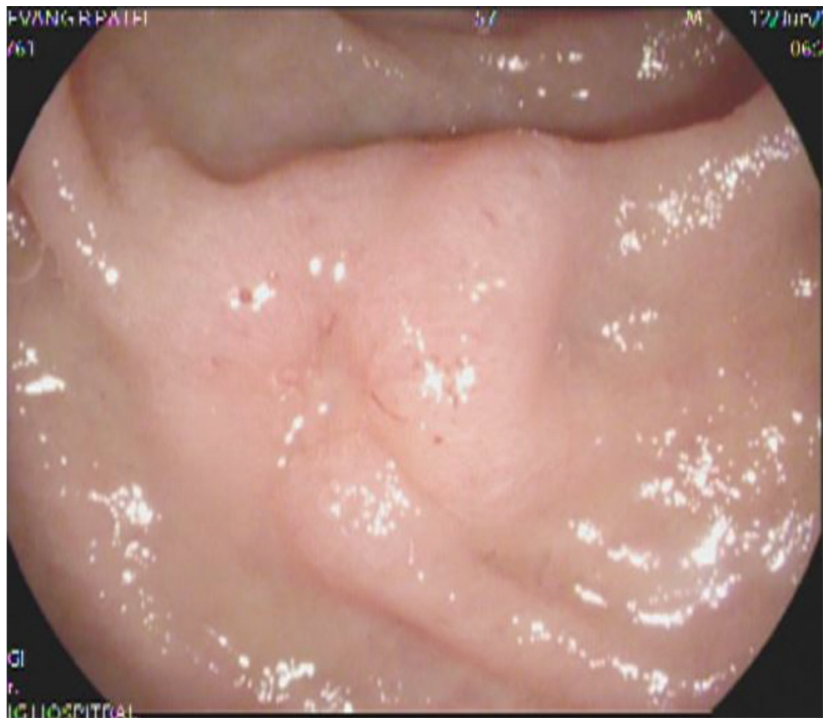

Fig. 1 Duodenal NET (D2). NET, neuroendocrine tumor.

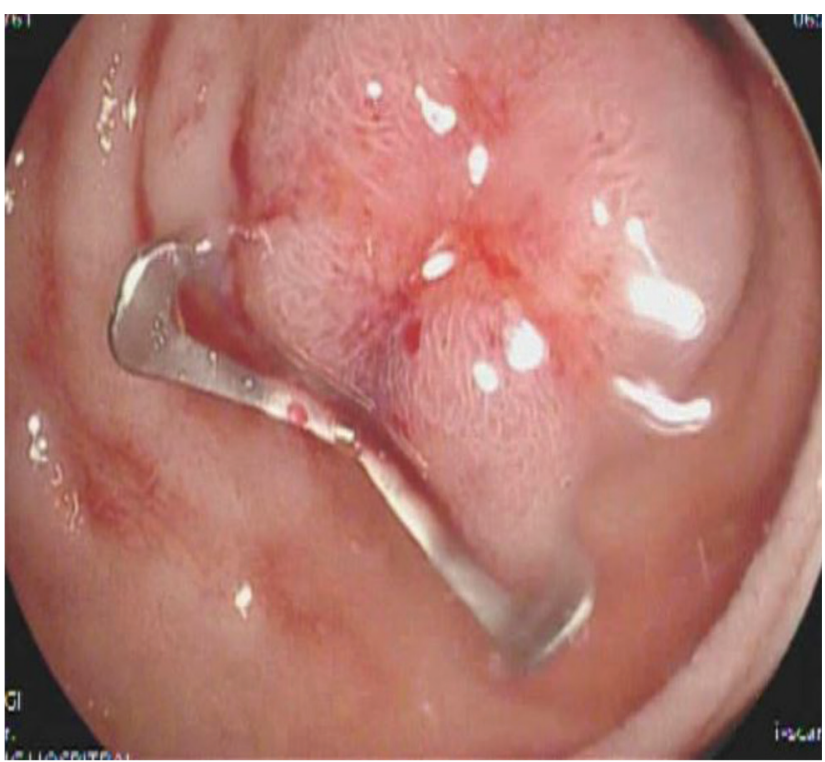

Fig. 2 Ovesco Clipping of D2 NET. NET, neuroendocrine tumor.

\section{Video 1}

Endoscopic Full Thickness Resection for Duodenal Neuroendocrine Tumor. Online content including video sequences viewable at: https://www.thieme-connect.com/products/ ejournals/html/10.1055/s-0039-3401446.

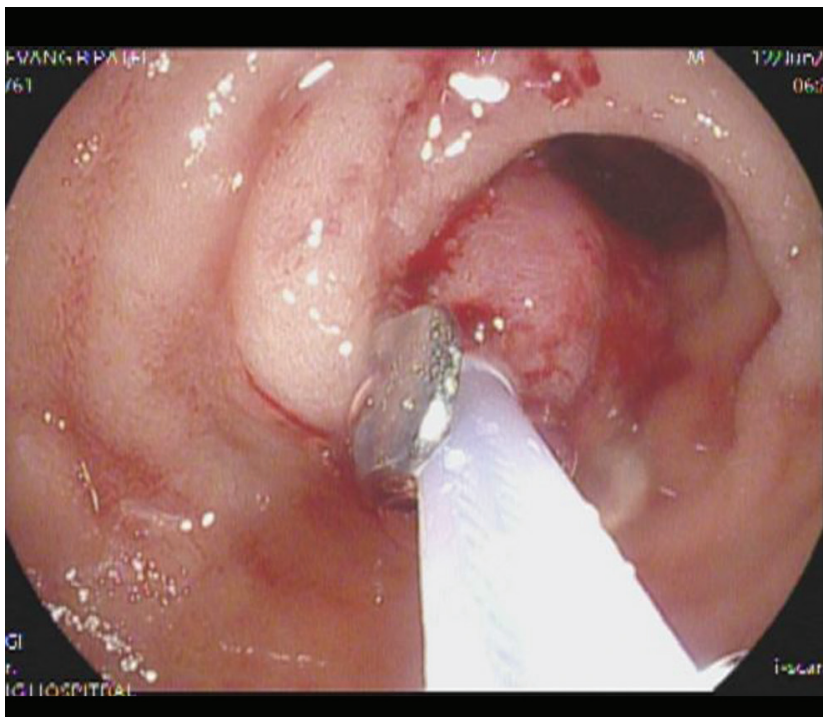

Fig. 3 Snare polypectomy of NET. NET, neuroendocrine tumor.

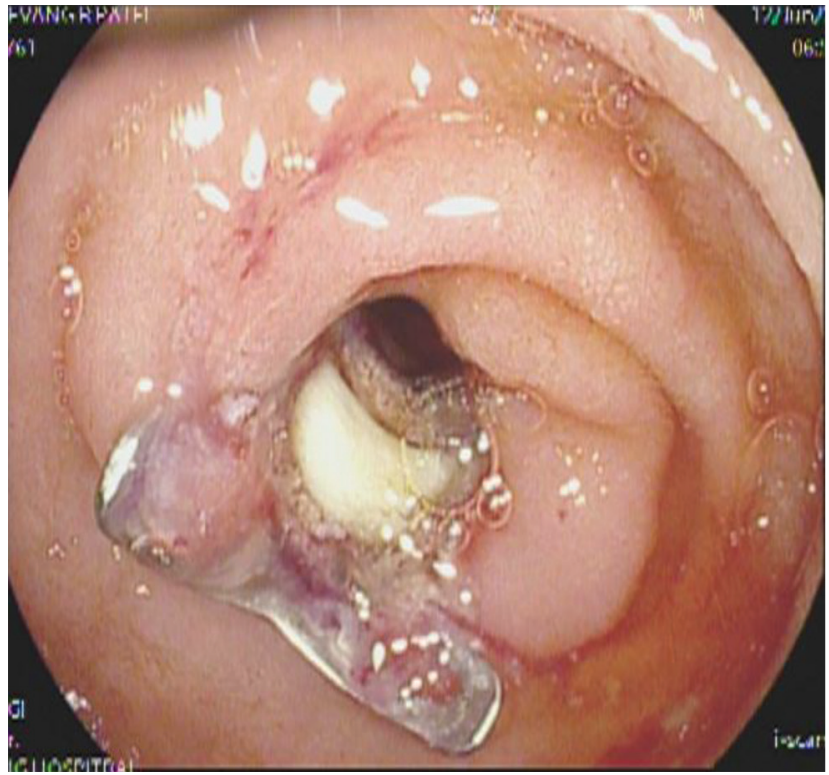

Fig. 4 Post snaring of D2 lesion. NET, neuroendocrine tumor.

\section{Conflict of Interest}

None declared. 